\title{
ON-LINE ASSESSMENT OF REGIONAL VENTRICULAR WALL MOTION BY TRANSESOPHAGEAL ECHOCARDIOGRAPHY WITH COLOR KINESIS DURING MINIMALLY INVASIVE CORONARY ARTERY BYPASS GRAFTING
}

Keiju Kotoh, MD

Go Watanabe, MD

Katsushi Ueyama, MD

Masayasu Uozaki, MD

Mamoru Suzuki, MD

Takurou Misaki, MD

Masahiro Wakasugi, $\mathrm{MD}^{\mathrm{b}}$

Yusuke Ito, $\mathrm{MD}^{\mathrm{b}}$
Objective: Our objective was to determine the changes in regional ventricular wall motion during minimally invasive direct coronary artery bypass grafting by color kinesis using transesophageal echocardiography. Methods: Minimally invasive coronary artery bypass grafting was performed in 34 patients, during which transesophageal echocardiography was used. Thirteen patients had isolated disease of the left anterior descending artery. Regional ventricular wall motion was analyzed by color kinesis with the SONOS 2500 transesophageal echocardiograph (Hewlett-Packard Co, Andover, Mass). On-line assessment of regional wall motion was continued during the operation. Results: Wall motion abnormalities during ischemia were present in 4 cases, left ventricular mid-anterior hypokinesis in 3 cases, and left ventricular apical-lateral hypokinesis in 1 case. In all cases, wall motion was maintained after bypass. In patients with total coronary occlusion, changes in wall motion did not occur during anastomosis. Conclusions: Color kinesis allowed us to evaluate the change in regional ventricular wall motion induced by myocardial ischemia during minimally invasive coronary artery bypass grafting both objectively and quantitatively. (J Thorac Cardiovasc Surg 1999;117:912-7) n minimally invasive cardiac surgery, transesophageal echocardiography is widely used to determine cardiac function or to monitor regional wall motion for myocardial ischemia. However, conventional 2-dimensional echocardiographic assessment of regional wall motion is experience dependent and subjective. To facilitate the evaluation of regional wall motion, color kinesis has been developed. ${ }^{1,2}$ Color kinesis can automatically determine the endocardial excursion by acoustic quantification and demonstrate the change in wall motion in color layers on a single end-systolic frame. Recent studies have demonstrated the validity of color kinesis for the evaluation of left ventricular wall motion in patients with coronary artery disease and dilated cardiomyopathy. ${ }^{3,4}$ However, experience in patients with acute myocardial ischemia or reper-

From the Departments of Surgery a and Anesthesiology, ${ }^{\mathrm{b}}$ Toyama Medical and Pharmaceutical University, Toyama, Japan.

Received for publication Sept 9, 1998; revisions requested Nov 6, 1998; revisions received Jan 11, 1999; accepted for publication Jan 12, 1999.

Address for reprints: Keiju Kotoh, MD, Department of Surgery, Toyama Medical and Pharmaceutical University, 2630 Sugitani, Toyama 930-0194, Japan.

Copyright (C) 1999 by Mosby, Inc.

$0022-5223 / 99 \$ 8.00+0 \quad \mathbf{1 2 / 1 / 9 7 0 4 8}$ fusion has not been reported. The purpose of this study was to evaluate color kinesis in assessing regional wall motion during temporary coronary occlusion and after reperfusion during minimally invasive coronary artery bypass grafting (CABG).

\section{Methods}

Patients. Thirty-four patients ( 27 men, 7 women; mean age $65.9 \pm 9.3$ years; range 48-83 years) referred for minimally invasive CABG between March 1997 and March 1998 were evaluated. Informed consent was obtained before the operation in all patients. Thirteen patients had isolated disease of the left anterior descending artery (LAD), and 21 patients had multivessel disease. Twelve patients had total obstruction of the LAD. The types of conduits and the grafted coronary arteries are shown in Table I. The left internal thoracic artery (LITA) was anastomosed to the LAD in all patients.

Operative procedures. The patients had high thoracic (T3/4 or T4/5) epidural catheters inserted 1 day before the operation. Thoracic epidural anesthesia concomitantly using sevoflurane and propofol was the primary type of anesthesia used for minimally invasive CABG. The cardiac sympathetic segment was blocked by thoracic epidural anesthesia, and the heart rate was usually stabilized at 45 to 60 beats/min without a $\beta$-blocker or calcium antagonist. The details of our surgical technique of minimally invasive CABG have been previously 


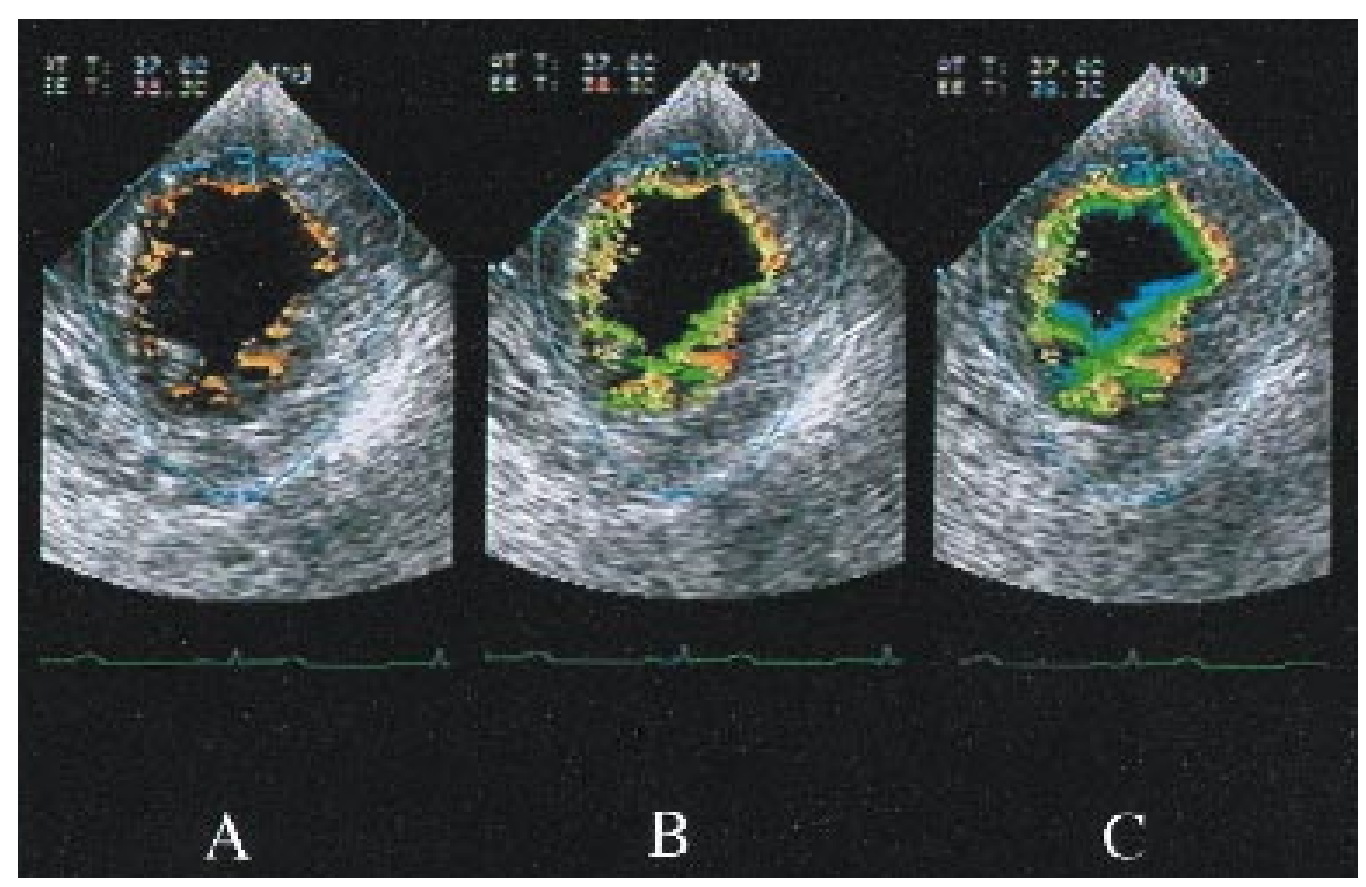

Fig 1. Example of 2-dimensional echocardiographic still frames obtained along the short-axis view at different times during systole with color kinesis: A, in early systole, $66 \mathrm{~ms}$ after the $\mathrm{R}$ wave; $\mathbf{B}$, in mid-systole, $165 \mathrm{~ms}$ after the R wave; $\mathbf{C}$, in end-systole, $363 \mathrm{~ms}$ after the R wave. From early systole to end-systole, an increasing number of colors was shown with progressive inward endocardial excursion.

reported by Watanabe and associates. ${ }^{5,6}$ Before the arterial conduits were divided, heparin sodium $(1.5 \mathrm{mg} / \mathrm{kg})$ was given intravenously. Before the anastomosis, nitroglycerin $(0.5$ $\mu \mathrm{g} / \mathrm{kg}$ per minute) and lidocaine hydrochloride $(1 \mathrm{mg} / \mathrm{kg})$ were given for myocardial protection, and a 5-minute coronary artery occlusion followed by a 5-minute period of reperfusion was performed to induced ischemic preconditioning. If significant electrocardiographic ST-segment changes occurred during ischemic preconditioning, we repeated intermittent occlusion several times. After the anastomosis, protamine sulfate $(0.75 \mathrm{mg} / \mathrm{kg})$ was given intravenously.

Echocardiography and color kinesis. After induction of anesthesia and endotracheal intubation, a multiplane transesophageal echocardiographic probe $(5 \mathrm{MHz}$, model 21364A; Hewlett-Packard Co, Andover, Mass) was inserted into the esophagus and connected to the SONOS 2500 echocardiographic system (Hewlett-Packard). The left ventricle was imaged along the long-axis, short-axis, and fourchamber views in sequence at first. Color kinesis was followed by continuous imaging in the transgastric short-axis and long-axis views during the coronary artery occlusion.

The color kinesis method compares backscatter values between successive acoustic frames and displays endocardial motion in color layers on a single end-systolic frame. ${ }^{1}$ The first frame begins after the $\mathrm{R}$ wave, and the interval of each frame is $33 \mathrm{~ms}$. A different color is added for each frame. The early systolic frame is orange, the mid-systolic frame is

\section{Table I. Clinical data of patients}

\begin{tabular}{lc}
\hline Age $(y)$ & $65.9 \pm 9.3$ \\
No. of stenosed vessels & \\
One & 13 \\
Two & 12 \\
Three & 9 \\
Left main & 4 \\
Total occlusion of LAD & 12 \\
Type of coronary artery bypass & 23 \\
LITA-LAD & 2 \\
LITA-LAD, GEA-RCA & 2 \\
LITA-LAD, RITA-RCA & 3 \\
LITA-LAD, GEA-Cx & 3 \\
LITA-LAD, LITA-RA-Cx & 1 \\
LITA-LAD, LITA-IEA-Cx, GEA-RCA & \\
\hline
\end{tabular}

$L A D$, Left anterior descending artery; LITA, left internal thoracic artery; GEA, gastroepiploic artery; $R C A$, right coronary artery; RITA, right internal thoracic artery; $C x$, circumflex artery; $R A$, radial artery; $I E A$, inferior epigastric artery.

green, and the end-systolic frame is blue. The last frame is $363 \mathrm{~ms}$ after the $\mathrm{R}$ wave (Fig 1). Baseline imaging was performed before the initial skin incision. On-line assessment of regional wall motion was continued from 15 minutes before coronary artery occlusion to the end of the operation. A regional wall motion abnormality was defined as decrease in the color layers of more than $3 \mathrm{~mm}$ or a decrease of more than 2 color frames $(66 \mathrm{~ms})$ in the color layer. 


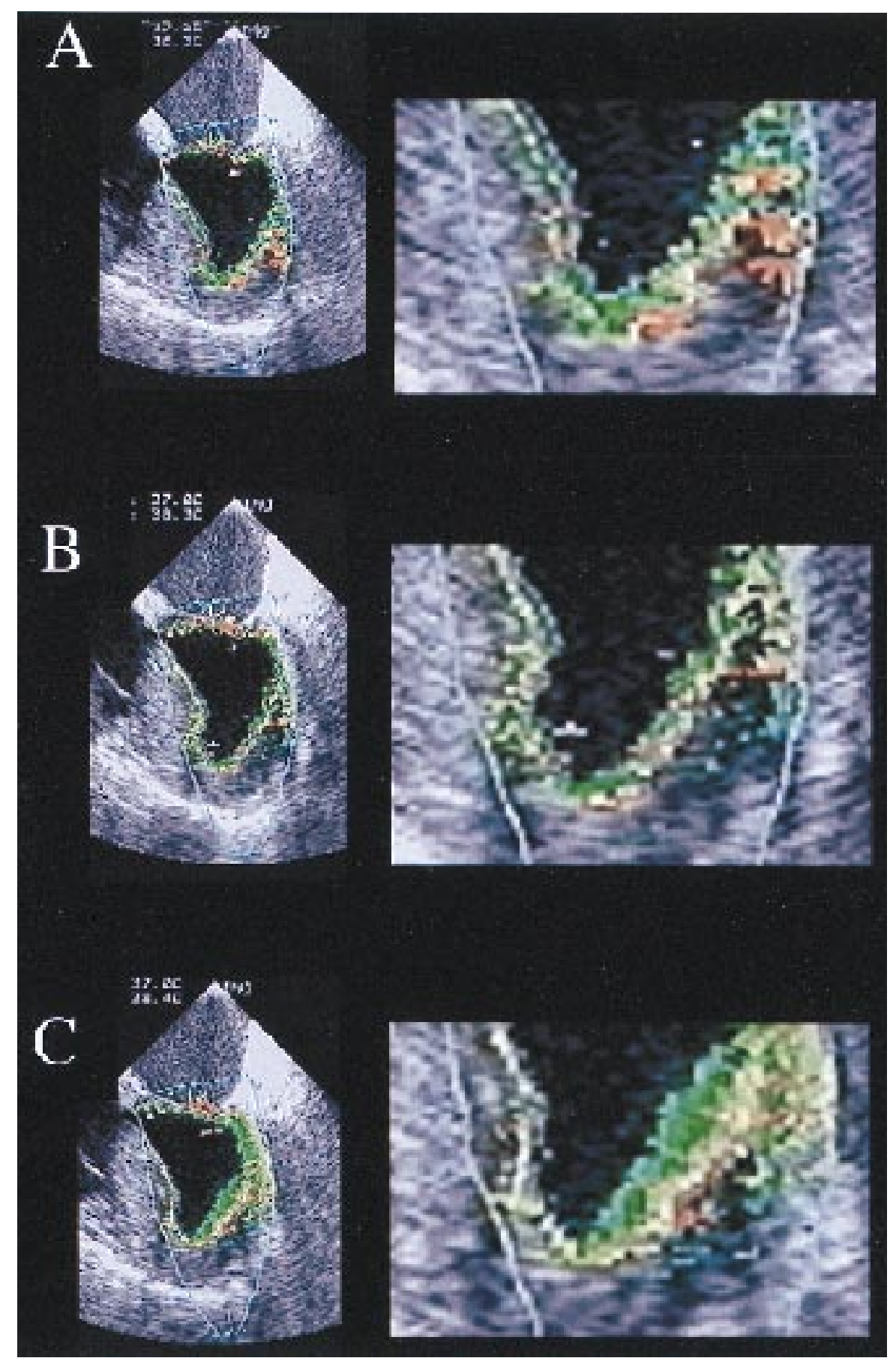

Fig 2. Example of color kinesis images obtained from a patient with apical-lateral hypokinesis: A, before occlusion of the LAD; B, 10 minutes after occlusion of the LAD; $\mathbf{C}, 10$ minutes after reperfusion of the LAD. The color layers were much thinner in the apical-lateral region during ischemia (B).

Electrocardiography. In all patients, standard extremity electrocardiographic leads were recorded during the operation. The epicardial electrocardiogram of the myocardial ischemic area was recorded in 14 patients. ST-segment eleva- tion or depression was measured to the nearest $0.5 \mathrm{~mm}$. An abnormal electrocardiographic response was defined as an ST-segment deviation of $1.0 \mathrm{~mm}$ or more.

Hemodynamic variables. Intraoperative hemodynamic 


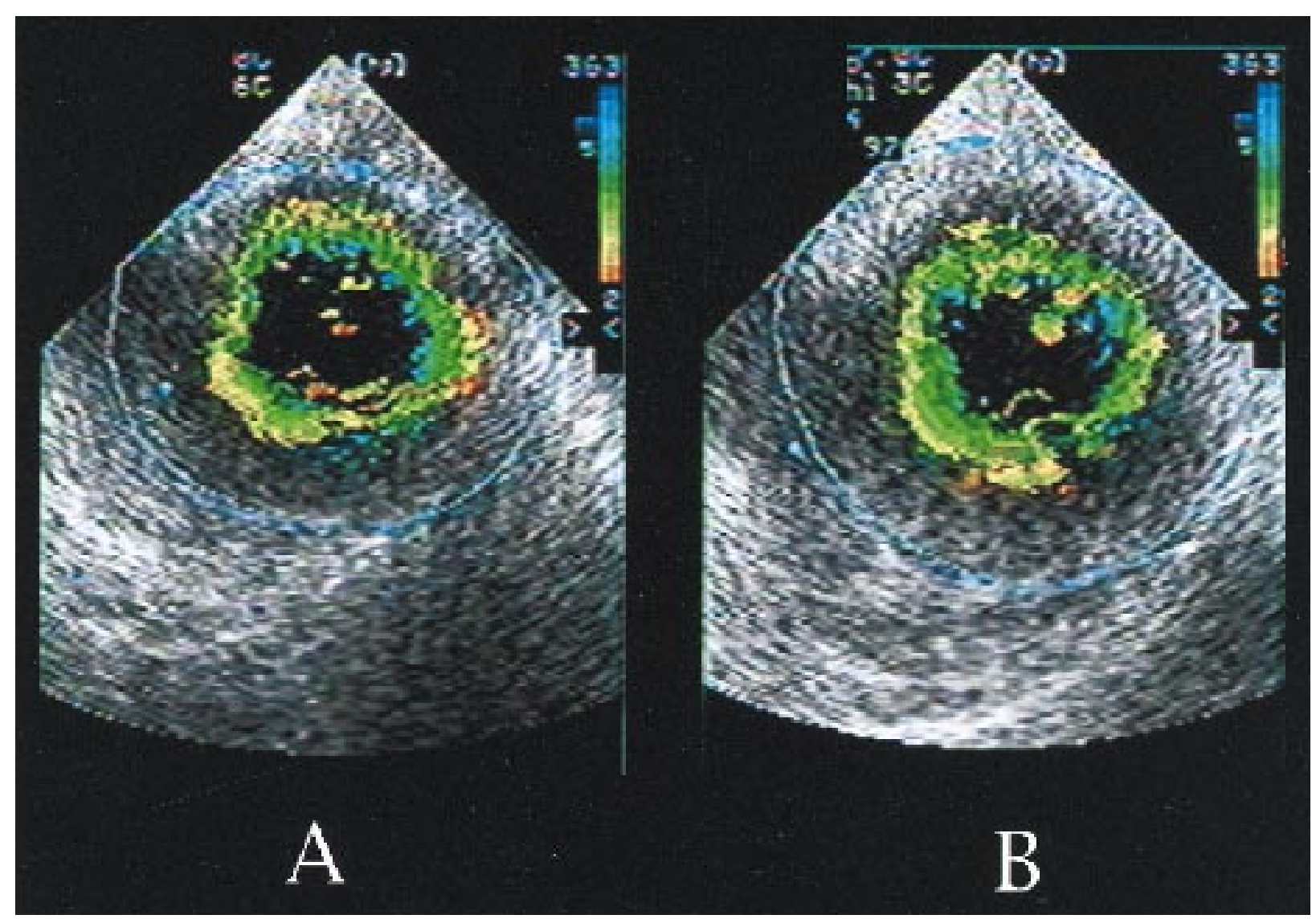

Fig 3. Example of color kinesis images from patients with minimally invasive CABG: A, before minimally invasive $\mathrm{CABG}$; $\mathbf{B}$, at the end of the $\mathrm{CABG}$ operation. The improvement of anteroseptal wall motion was shown by the presence of much thicker color layers after minimally invasive CABG.

variables were recorded for each stage 5 minutes before the coronary artery occlusion, 5 minutes after the coronary occlusion, and 5 minutes after the coronary artery reperfusion. Systolic blood pressure readings were obtained from an arterial catheter, and pulmonary artery systolic and diastolic pressure readings were obtained from a pulmonary artery catheter. The cardiac index was measured by a thermodilution method.

Statistical analysis. All values are expressed as mean \pm standard deviation. Mean values were analyzed with the paired Student $t$ test.

\section{Result}

Color kinesis findings. Color kinesis was performed in all patients in this study. Wall motion abnormalities during temporary coronary occlusion were detected in 4 cases (12\%), left ventricular mid-anterior hypokinesis in 3 cases, and left ventricular apical-lateral hypokinesis in 1 case. Of the 3 patients with mid-anterior hypokinesis, 2 had multivessel disease and 1 had single-vessel disease. Wall motion abnormalities were
Table II. Hemodynamic variables

\begin{tabular}{lccc}
\hline & $\begin{array}{c}\text { Before } \\
\text { occlusion }\end{array}$ & Occlusion & Reperfusion \\
\hline $\begin{array}{l}\text { Systolic blood pressure } \\
(\mathrm{mm} \mathrm{Hg})\end{array}$ & $97 \pm 8$ & $94 \pm 8$ & $100 \pm 8$ \\
$\begin{array}{l}\text { Systolic pulmonary pressure } \\
(\mathrm{mm} \mathrm{Hg})\end{array}$ & $23 \pm 3.8$ & $23 \pm 4.3$ & $22 \pm 3.3$ \\
$\begin{array}{l}\text { Diastolic pulmonary pressure } \\
(\mathrm{mm} \mathrm{Hg})\end{array}$ & $12 \pm 3.0$ & $13 \pm 3.1$ & $12 \pm 2.7$ \\
$\begin{array}{l}\text { Heart rate (beats/min) } \\
\text { Cardiac index }\left(\mathrm{mL} / \mathrm{min} / \mathrm{m}^{2}\right)\end{array}$ & $61 \pm 6$ & $62 \pm 8$ & $65 \pm 9$ \\
\hline
\end{tabular}

detected during the creation of the LITA-LAD anastomoses in these patients. The patient with apical-lateral hypokinesis had 3-vessel disease, and hypokinesis was detected during the creation of the LITA-LAD anastomosis (Fig 2). In all patients, wall motion normalized within 5 minutes of reperfusion. Changes in wall 
motion during creation of the anastomosis were not observed in patients with total coronary occlusion. Left ventricular wall motion, as measured by color kinesis, had improved by the end of minimally invasive CABG in 7 patients (Fig 3).

Hemodynamic variables. Systolic blood pressure during temporary coronary occlusion $(94 \pm 8 \mathrm{~mm} \mathrm{Hg})$ was decreased significantly in comparison with the measurement taken 5 minutes before coronary artery occlusion (97 $\pm 8 \mathrm{~mm} \mathrm{Hg} ; P=.037)$ and 5 minutes after coronary artery reperfusion $(100 \pm 8 \mathrm{~mm} \mathrm{Hg} ; P=$ .0008). Pulmonary artery systolic and diastolic pressure, cardiac index, and heart rate did not change significantly (Table II).

Electrocardiographic findings. Significant electrocardiographic ST changes occurred in 4 patients (12\%) during creation of the LITA-LAD anastomoses. The ST changes were recorded simultaneously with both the extremity electrocardiographic leads and the epicardial electrocardiograms. In 1 of these 4 patients, we observed an impairment of wall motion by color kinesis and found an isolated $70 \%$ obstruction of the left main trunk. The other patients had greater than $90 \%$ stenosis of the proximal LAD.

\section{Discussion}

Color kinesis can easily and objectively evaluate regional wall motion by changes in color tone, because it uses acoustic quantification to represent the systolic endocardial excursion by time phase. Accordingly, it has been reported that color kinesis can reduce interobserver variability resulting from differences in experience, which has been a problem in 2-dimensional echocardiography, and that even an unskilled observer can help to evaluate wall motion easily and accurately. ${ }^{7}$ Moreover, this method can help to evaluate wall motion continuously in real time. On the basis of these findings, color kinesis is considered to be extremely useful in evaluating wall motion changes during minimally invasive direct CABG in which ischemia of the coronary artery is inevitable.

A difference was seen between the detection of the wall motion abnormalities and electrocardiographic ST changes. For 4 patients in our study, color kinesis recorded a reduction in regional wall motion in the ischemic area. However, only 1 of these patients had ST changes during coronary artery occlusion. It has been reported that reduced regional wall motion during ischemia is not always associated with ST changes. ${ }^{8,9}$ Therefore, color kinesis may provide a more sensitive means to monitor localized ischemia during surgery. On the other hand, electrocardiographic abnormalities were recorded without wall motion abnormalities in 3 patients. In minimally invasive $\mathrm{CABG}$, the pericardium was displaced to facilitate anastomosis, especially during anastomoses to the circumflex or right coronary artery. We occasionally observed that the echocardiographic views of the left ventricle were limited after pericardial traction during that time. In these cases, transesophageal echocardiography may be insufficient to evaluate wall motion.

Color kinesis has several limitations. First, color kinesis is affected by cardiac translation owing to ventilation and rotation. ${ }^{10}$ During surgery, however, cardiac translation can be controlled by using manual ventilation. Next, in 2-dimensional echocardiography, wall motion abnormalities are evaluated by wall motion and wall thickness. Color kinesis assesses wall motion, but not wall thickness. Thus the efficacy of color kinesis in this regard has not been determined yet. Recently, several attempts have been made to make color kinesis more quantitative. A segmental analysis of color kinesis provides quantitative indices of magnitude and timing of regional endocardial motion. ${ }^{11}$ Another method assesses the velocity of endocardial motion with color kinetic images. ${ }^{12}$ We hope these methods will permit quantitative analysis of wall motion in the future.

\section{Conclusion}

Color kinesis by acoustic quantification can help to evaluate the reduction in regional wall motion resulting from ischemia of the myocardium in minimally invasive CABG. This method is considered to be extremely easy and effective in monitoring circulatory kinetics by transesophageal echocardiography during minimally invasive $\mathrm{CABG}$.

\section{REFERENCES}

1. Lang RM, Vignon P, Weinert L, Bednarz J, Korcarz C, Sandelski $\mathrm{J}$, et al. Echocardiographic quantification of regional left ventricular wall motion with color kinesis. Circulation 1996;93:1877-85.

2. Schwartz SL, Cao QL, Vannan MA, Pandian NG. Automatic backscatter analysis of regional left ventricular systolic function using color kinesis. Am J Cardiol 1996;77:1345-50.

3. Godoy I, Mor-Avi V, Weinert L, Vignon P, Korcarz C, Spencer $\mathrm{KT}$, et al. Use of color kinesis for evaluation of left ventricular filling in patients with dilated cardiomyopathy and mitral regurgitation. J Am Coll Cardiol 1998;31:1598-606.

4. Hartmann T, Kolev N, Blaicher A, Spiss C, Zimpfer M. Validity of acoustic quantification color kinesis for detection of left ventricular regional wall motion abnormalities: a transoesophageal echocardiographic study. Br J Anaesth 1997;79:482-7.

5. Watanabe G, Misaki T, Kotoh K, Abe Y, Yamamoto A, Ueyama K. Bilateral minimally invasive direct coronary artery bypass grafting with the use of two arterial grafts. J Thorac Cardiovasc Surg 1997; 113:949-51. 
6. Watanabe G, Misaki T, Kotoh K, Yamashita A, Ueyama K. Bilateral thoracoscopic minimally invasive direct coronary artery bypass grafting using internal thoracic arteries. Ann Thorac Surg 1998;65:1673-5.

7. Kawai J, Yoshida K, Hozumi T, Akasaka T, Takagi T, Yamamuro A, et al. Evaluation of left ventricular wall motion by color kinesis: comparison of assessment of left ventricular wall motion by experienced and inexperienced observers. Jpn J Med Ultrasonics 1996;23:821-4.

8. Battler A, Froelicher VF, Gallagher KP, Kemper WS, Ross J. Dissociation between regional myocardial dysfunction and ECG changes during ischemia in the conscious dog. Circulation 1980;62:735-44.

9. Sugishita Y, Koseki S, Matsuda M, Tamura T, Yamaguchi I, Ito I. Dissociation between regional dysfunction and ECG changes during myocardial ischemia induced by exercise in patients with angina pectoris. Am Heart J 1983;106:1-8.

10. Gillam LD, Hogan RD, Foale RA, Franklin TD, Newell JB, Guyer DE, et al. A comparison of quantitative echocardiographic methods for delineating infarct-induced abnormal wall motion. Circulation 1984;70:113-22.

11. Mor-Avi V, Vignon P, Koch R, Weinert L, Garcia MJ, Spencer KT, et al. Segmental analysis of color kinesis images: new method for quantification of the magnitude and timing of endocardial motion during left ventricular systole and diastole. Circulation 1997;95:2082-97.

12. Vandenberg BF, Oren RM, Lewis J, Aeschilman S, Burns TL, Kerber RE. Evaluation of color kinesis: a new echocardiographic method for analyzing regional wall motion in patients with dilated left ventricles. Am J Cardiol 1997;79:645-50. 